\title{
NGHIÊN CỨU, XÂY DỰNG PHÁT TRIỂN CÁC MÔ HìNH PHÂN CHIA SẢN PHẨM TẠI CÁC MỎ KẾT NỐI CỦA VIETSOVPETRO
}

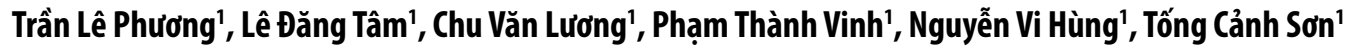 \\ Nguyễn Viết Văn², Đỗ Dương Phương Thảo ${ }^{1}$, A.G. Axmadev ${ }^{1}$, Châu Nhật Bằng ${ }^{1}$, Nguyễn Hữu Nhân' ${ }^{1}$, Đoàn Tiến Lữ \\ Trần Thị Thanh Huyền', Lê Thị Đoan Trang', Bùi Mai Thanh Tú' \\ "Liên doanh Việt - Nga "Vietsovpetro" \\ ${ }^{2}$ Công ty Liên doanh Điều hành Hoàng Long - Hoàn Vũ \\ Email:vinhpt.rd@vietsov.com.vn \\ https://doi.org/10.47800/PVJ.2021.01-02
}

\section{Tóm tắt}

Kết nối mỏ là giải pháp tận dụng cơ sở hạ tầng vật chất hiện hữu của các mỏ lớn để kết nối, phát triển các mỏ nhỏ, mỏ cận biên. Phương thức này cho phép gia tăng hiệu quả kinh tế các mỏ có trữ lượng trung bình và nhỏ, mở ra triển vọng phát triển và đưa các mỏ dầu nhỏ, hạn chế về trữ lượng vào khai thác sớm.

Quá trình kết nối mỏ có thách thức khác nhau về mặt kỹ thuật và kinh tế, khả năng kết nối, thu gom, mức độ cải hoán hệ thống công nghệ để tiếp nhận, phân chia sản phẩm... Đối với trường hợp kết nối các mỏ vào hệ thống công nghệ thuộc chủ sở hữu khác, vấn đề phân chia sản phẩm có ý nghĩa quan trọng liên quan đến lợi ích trực tiếp của các chủ đầu tư.

Bài báo phân tích các mô hình phân chia sản phẩm của Liên doanh Việt - Nga “Vietsovpetro" đang áp dụng cho các mỏ kết nối, đánh giá khả năng cập nhật/nâng cấp các phần mềm mô phỏng có độ tin cậy cao, cho phép đánh giá nhanh về mặt kỹ thuật sự thay đổi của lưu lượng chất lưu trong hệ thống khi qua các quá trình xử lý công nghệ.

Từ khóa: Kết nối mỏ, vận chuyển dầu và khí, phân chia sản phẩm.

\section{Giới thiệu}

Đến cuối năm 2020, Vietsovpetro đã kết nối thành công các mỏ như: Cá Ngừ Vàng, Nam Rồng - Đồi Mồi, Gấu Trắng, Thỏ Trắng... với các mỏ Bạch Hổ và Rồng, mang lại hiệu quả kinh tế to lớn cho các nhà điều hành khác. Khi sản lượng dầu khai thác tại các mỏ suy giảm, Vietsovpetro đã tập trung nghiên cứu, triển khai giải pháp kết nối các mỏ dự kiến khai thác nằm bên cạnh các mỏ Bạch Hổ và Rồng để tận dụng công suất xử lý chất lỏng của thiết bị còn dư tại 2 mỏ này. Việc mở rộng kết nối các mỏ dầu lân cận với mỏ Bạch Hổ và Rồng sẽ mở ra triển vọng phát triển và đưa các mỏ dầu lân cận có trữ lượng thấp vào khai thác sớm.

Hiện nay, Vietsovpetro đã kết nối các mỏ Cá Ngừ Vàng, Nam Rồng - Đồi Mồi, Cá Tầm, 04/3... vào hệ thống. Vietsovpetro đã vận dụng, nghiên cứu và xây dựng các mô hình

Ngày nhận bài: 26/12/2020. Ngày phản biện đánh giá và sửa chũa: 26/12/2020 - 6/1/2021. Ngày bài báo được duyệt đăng: 7/1/2021. phân chia sản phẩm khác nhau với tính chính xác và chi phí vận hành ở mức hợp lý được các bên đồng thuận sử dụng.

\section{Các mô hình phân chia sản phẩm tại các mỏ kết nối của Vietsovpetro}

Phân chia sản phẩm khai thác được hiểu là xác định lượng hydrocarbon đo được từ các nguồn khác nhau [1]. Phân chia sản phẩm là hoạt động phổ biến ở các mỏ kết nối sử dụng hệ thống công nghệ thu gom, vận chuyển, tàng trữ sản phẩm khai thác chung.

Quá trình phân chia sản phẩm dựa trên các kết quả đo đếm vật lý khác nhau: khối lượng, thể tích, năng lượng. Trong đó phân chia theo khối lượng, thể tích phổ biến cho những trường hợp phân chia hydrocarbon lỏng, phân chia theo năng lượng thường được sử dụng cho phân chia sản phẩm khai thác ở dạng khí.

Dựa trên những điều kiện cụ thể của hệ thống công nghệ thu gom, đo lường sản phẩm khai thác và 
trên cơ sở thỏa thuận giữa các bên liên quan mà có các nguyên lý phân chia khác nhau. Các nguyên lý phân chia phổ biến là:

- Phân chia sản phẩm theo khối lượng theo nguyên tắc phân chia ngược;

- Phân chia sản phẩm theo đơn vị thể tích theo nguyên tắc phân chia ngược;

- Phân chia sản phẩm theo thành phần chất lưu;

- Phân chia sản phẩm theo các mô hình mô phỏng, tính toán.

Nguyên lý phân chia sản phẩm theo nguyên tắc phân chia ngược được sử dụng và thừa nhận rộng rãi trong ngành công nghệ khai thác dầu và khí [1]. Trong mô hình phân chia sản phẩm theo nguyên tắc ngược xét có $n$ nguồn hydrocarbon vận chuyển ra điểm $B$ để xử lý và tàng trữ, với lưu lượng dầu thể tích đo được tại $B$ quy về cùng một điều kiện. Theo đó, lưu lượng hydrocarbon phân chia cho từng nguồn $(i=1 \ldots n)$ sẽ là:

$$
\begin{aligned}
& Q_{i i=1 \ldots n}=k_{\text {back allocation }} \times Q_{\text {imeasured }} \\
& k_{\text {back allocation }}=\frac{Q_{B}}{\sum_{Q i}^{i=1 \ldots n}}
\end{aligned}
$$

Trong đó:

$\mathrm{Q}_{\mathrm{ii}=1 \text {. }}$ : Lượng hydrocarbon được phân chia cho nguồn $\mathrm{i}$;

$\mathrm{Q}_{\text {imeasured }}$ : Lưu lượng thể tích dầu đo được ở cùng một điều kiện.
Lượng dầu đo được tại các công trình $X$ quy về điều kiện chuẩn được xác định dựa trên các tham số sau:

- Hàm lượng nước $W_{x}$ i

- Lưu lượng theo thể tích chất lỏng ở điều kiện vận hành $\mathrm{V}_{\mathrm{x}}$;

- Hệ số co ngót dầu của công trình $X, S_{X}$.

Phân chia sản phẩm theo các mô hình mô phỏng, sử dụng các công cụ tính toán của phần mềm (như HYSYS, PVTSIM, UNIX...) để xác định lượng hydrocarbon lỏng được phân chia cho từng nguồn.

\subsection{Phân chia sản phẩm mỏ Nam Rồng - Đồi Mồi}

Mỏ Nam Rồng - Đồi Mồi được kết nối vào hệ thống thu gom, vận chuyển sản phẩm khai thác mỏ Rồng, Vietsovpetro. Mỏ Nam Rồng - Đồi Mồi có 2 giàn nhẹ được khai thác là RC-DM, RC-4.

Sản phẩm khai thác RC-DM, RC-4, RC-5 cùng với RC-6 được vận chuyển về RP-1 để tách khí và bơm về tàu nổi chứa dầu FSO-6 để xử lý, tàng trữ và xuất bán. Tại FSO-6 đồng thời tiếp nhận các nguồn dầu bơm từ RP-2 bao gồm dầu mỏ Cá Tầm, RP-3. Sơ đồ thu gom vận chuyển và phân chia dòng dầu được thể hiện tại Hình 1 và 2.

Lượng dầu $\mathrm{Q}\left(\mathrm{sm}^{3}\right)$ đo được tại các công trình RP-1, RP-2, Cá Tầm, RP-3 được quy về điều kiện chuẩn thông qua hệ số co ngót $S$ từ lượng dầu $V\left(\mathrm{~m}^{3}\right)$ đo được ở điều kiện vận hành:

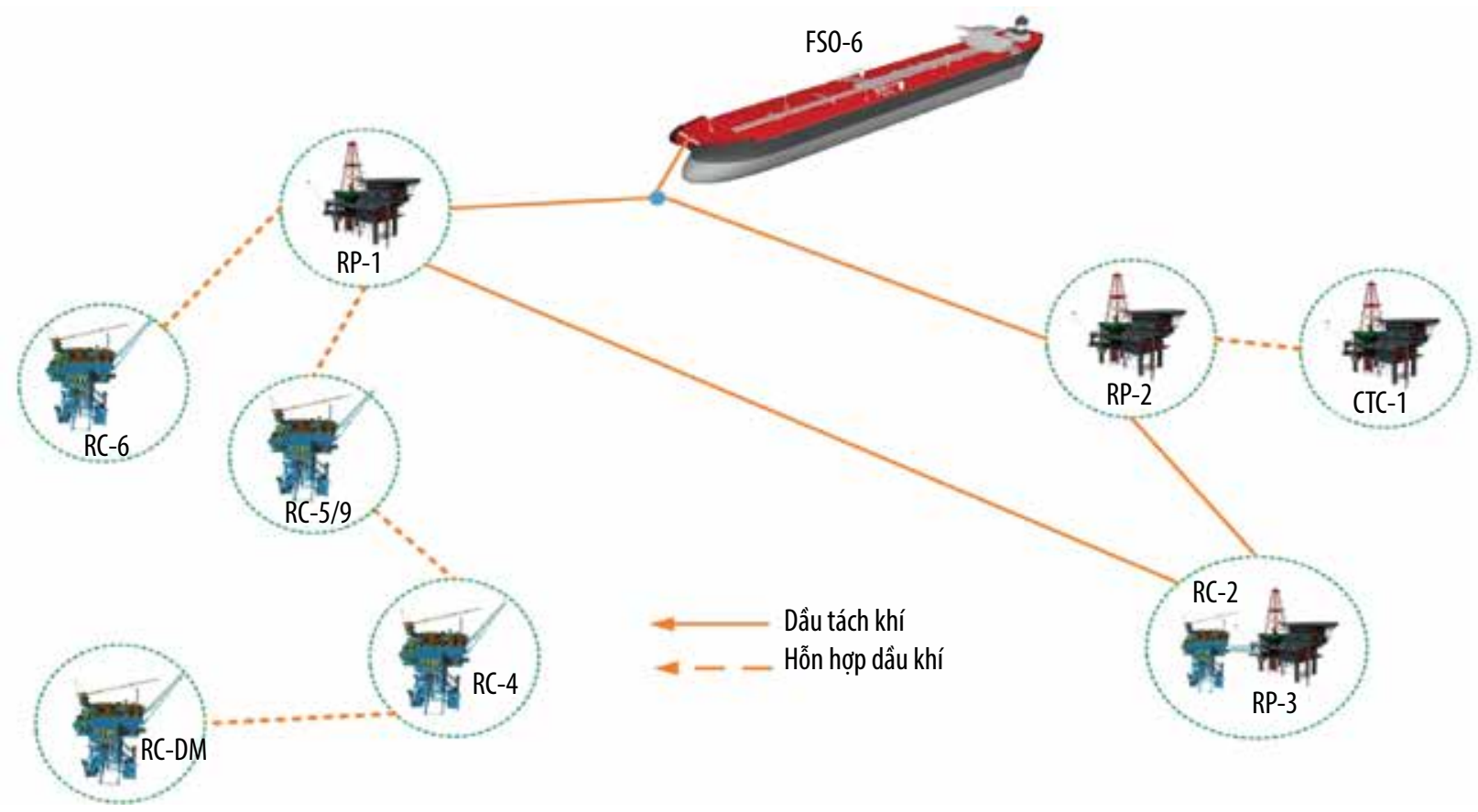

Hinh 1. Sơđồ thu gom sản phẩm khai thác tại mỏ Nam Rồng - Đồi Mồi 


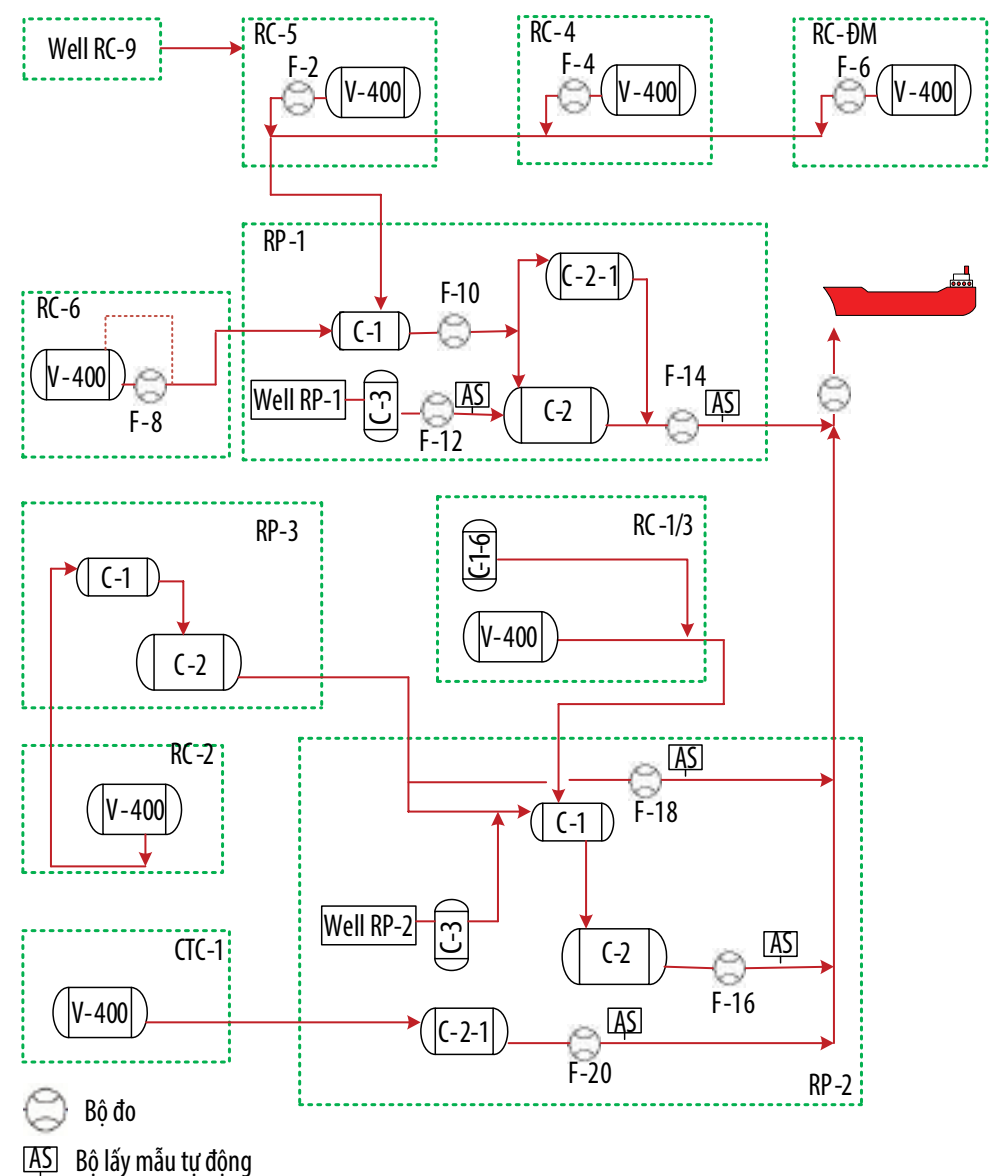

Hình 2. Sơ đồ phân chia dòng dâu mỏ Nam Rồng - Đồi Mồi

$$
\begin{gathered}
Q_{S C O / R P Z_{-} F S O}=V_{o i l / R P 2} \times S_{o i l / R P 2} \\
Q_{S C O / R P 3_{-} F S O}=V_{o i l / R P 3} \times S_{o i l / R P 3} \\
Q_{S C O / C T_{-} F S O}=V_{o i l / C T} \times S_{o i l / C T} \\
Q_{S C O / R P 1_{-} F S O}=V_{o i l / R P 1} \times S_{o i l / R P 1}
\end{gathered}
$$

Hệ số bất cân bằng $\mathrm{K}_{\mathrm{imb}}$ được định nghĩa là hệ số thể hiện sự bất cân bằng giữa tổng lượng dầu quy về điều kiện chuẩn của các nguồn dầu bơm ra tàu $\mathrm{FSO}$ và lượng dầu đo được tại $\mathrm{FSO}_{\mathrm{SCO} / F \mathrm{SO}^{\prime}}$ tính theo công thức:

$$
K_{i m b}=\frac{Q_{\text {SCO/FSO }}}{Q_{\text {SCO/RP1_FSO }}+Q_{\text {SCO/RP2_FSO }}+Q_{\text {SCO/CT_FSO }}+Q_{S C O / R P 3_{-} F S O}}
$$

Lượng dầu đo được tại các công trình RC-6, RC-5, RC-4, RC-DM, RP-1 được xác định như sau:

$$
\begin{gathered}
Q_{S C O / R C 6}=V_{f / R C 6} \times\left(1-0,01 \times W_{R C 6}\right) \times S_{R C 6} \\
Q_{S C O / R C 5}=V_{f / R C 5} \times\left(1-0,01 \times W_{R C 5}\right) \times S_{R C 5} \\
Q_{S C O / R C 4}=V_{f / R C 4} \times\left(1-0,01 \times W_{R C 4}\right) \times S_{R C 4} \\
Q_{S C O / R C D M}=V_{f / R C D M} \times\left(1-0,01 \times W_{R C D M}\right) \times S_{R C D M} \\
Q_{S C O / C 3}=V_{f / R P 1} \times\left(1-0,01 \times W_{C 3}\right) \times S_{C 3} \\
Q_{S C O / C 1}=V_{f / C 1} \times\left(1-0,01 \times W_{C 1}\right) \times S_{C 1}
\end{gathered}
$$

Hệ số $\mathrm{K}_{\mathrm{a}}$ hiệu chỉnh lượng dầu cho RP-1 được xác định như sau:

$$
K_{a}=\frac{Q_{S C O / R P 1_{1} F O}}{Q_{S C O / C 1}+Q_{S C O / C 3}}
$$

Hệ số $\mathrm{K}_{\mathrm{b}}$ hiệu chỉnh lượng dầu đo được tại RP-1 so với tổng lượng dầu từ các giàn RC-DM, $\mathrm{RC}-4, \mathrm{RC}-5, \mathrm{RC}-6$ bơm về RP-1 được xác định như sau:

$$
K_{b}=\frac{Q_{S C O / C 1}}{Q_{S C O / R C 6}+Q_{S C O / R C 5}+Q_{S C O / R C 4}+Q_{S C O / R C D M}}
$$

Lượng dầu phân chia cho các công trình RC$\mathrm{DM}, \mathrm{RC}-4$ được xác định theo nguyên tắc phân chia ngược như sau:

$$
\begin{gathered}
Q_{S C O / R C A_{-} F S O}=K_{i m b} \times K_{a} \times K_{b} \times Q_{S C O / R C 4} \\
Q_{S C O / R C D M \_F S O}=K_{i m b} \times K_{a} \times K_{b} \times Q_{S C O / R C D M}
\end{gathered}
$$

\subsection{Phân chia sản phẩm mỏ Cá Ngừ Vàng}

Sản phẩm khai thác từ mỏ Cá Ngừ Vàng được vận chuyển về giàn công nghệ trung tâm CTP3 để xử lý. Dầu Cá Ngừ Vàng xử lý tách nước và được bơm về FSO để tàng trữ cùng với dầu khai thác từ mỏ Bạch Hổ (giàn CTP-3 và giàn CTP-2).

Sơ đồ thu gom sản phẩm khai thác của mỏ Cá Ngừ Vàng được thể hiện tại Hình 3. Sản phẩm khai thác mỏ Cá Ngừ Vàng đi vào 1 trong 3 đường công nghệ của CTP-3 để tách khí và nước. Dầu Cá Ngừ Vàng có thể được xử lý theo đường công nghệ riêng hoặc được trộn với dầu mỏ Bạch Hổ để tách khí nước và bơm về FSO.

- Trường hợp dầu Cá Ngừ Vàng đi theo đường công nghệ riêng

Lượng dầu $\mathrm{Q}\left(\mathrm{sm}^{3}\right)$ đo được tại các công trình CTP-2, CTP-3, dầu Cá Ngừ Vàng được quy về điều kiện chuẩn thông qua hệ số co ngót $\mathrm{S}$ từ lượng dầu $\mathrm{V}\left(\mathrm{m}^{3}\right)$ đo được ở điều kiện vận hành:

$$
\begin{aligned}
Q_{\text {SCO/CTP___FSO }} & =V_{\text {oil/CTP2 }} \times S_{\text {oil/CTP2 }} \\
Q_{\text {SCO/CTP__FSO }} & =V_{\text {oil/RP3 }} \times S_{\text {oil/CTP3 }} \\
Q_{\text {SCO/CNV_FSO }} & =V_{\text {oil/CNV }} \times S_{\text {oil/CNV }}
\end{aligned}
$$

Hệ số bất cân bằng $\mathrm{K}_{\mathrm{imb}}$ được địinh nghĩa là hệ số thể hiện sự bất cân bằng giữa tổng lượng dầu quy về điều kiện chuẩn của các nguồn dầu bơm ra FSO và lượng dầu đo được tại $\mathrm{FSO}_{{\mathrm{sco} / F \mathrm{Fo}^{\prime}}}$ tính theo công thức: 


$$
K_{i m b}=\frac{Q_{\text {SCO/FSO }}}{Q_{\text {SCO/CTP-2_FSO }}+Q_{S C O / C T P 3_{-} F S O}+Q_{S C O / C N V_{-} F S O}}
$$

Lượng dầu chia cho mỏ Cá Ngừ Vàng được xác định như sau:

$$
Q_{\text {Allocated_SCO/CNV_FSO }}=Q_{\text {SCO/CNV_FSO }} \times K_{\text {imb }}
$$

- Trường hợp dầu trộn dầu Cá Ngừ Vàng và Bạch Hổ

Lượng dầu $\mathrm{Q}\left(\mathrm{sm}^{3}\right)$ đo được tại các công trình CTP-2, CTP-3,

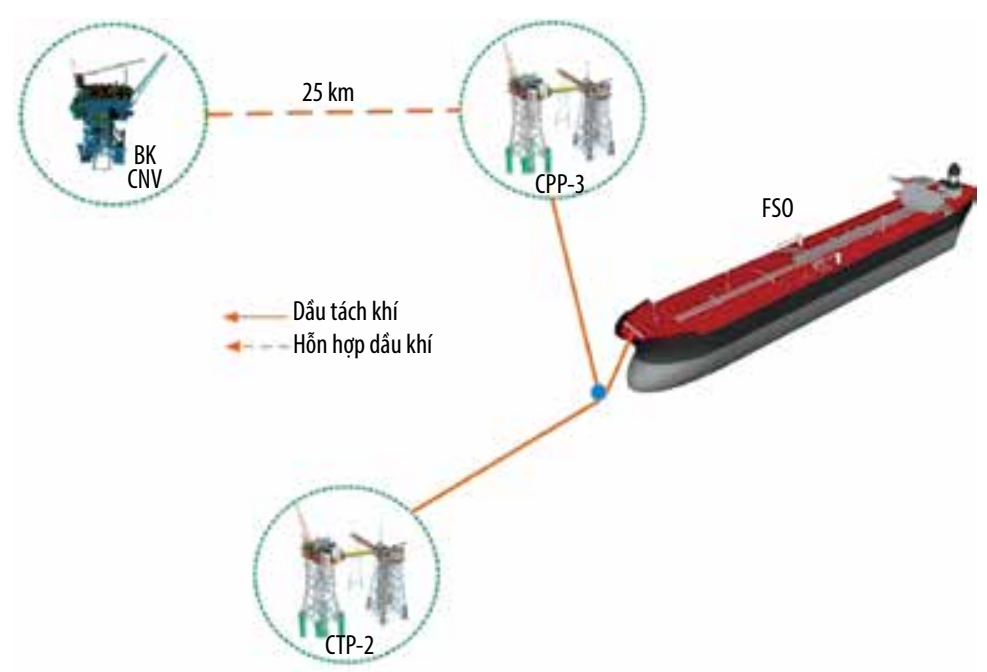

Hình 3. Sơ đồ thu gom sản phẩm khai thác tại mỏ Cá Ngừ Vàng

Hình 4. Sơ đồ phân chia dòng dầu khai thác từ mỏ Cá Ngừ Vàng

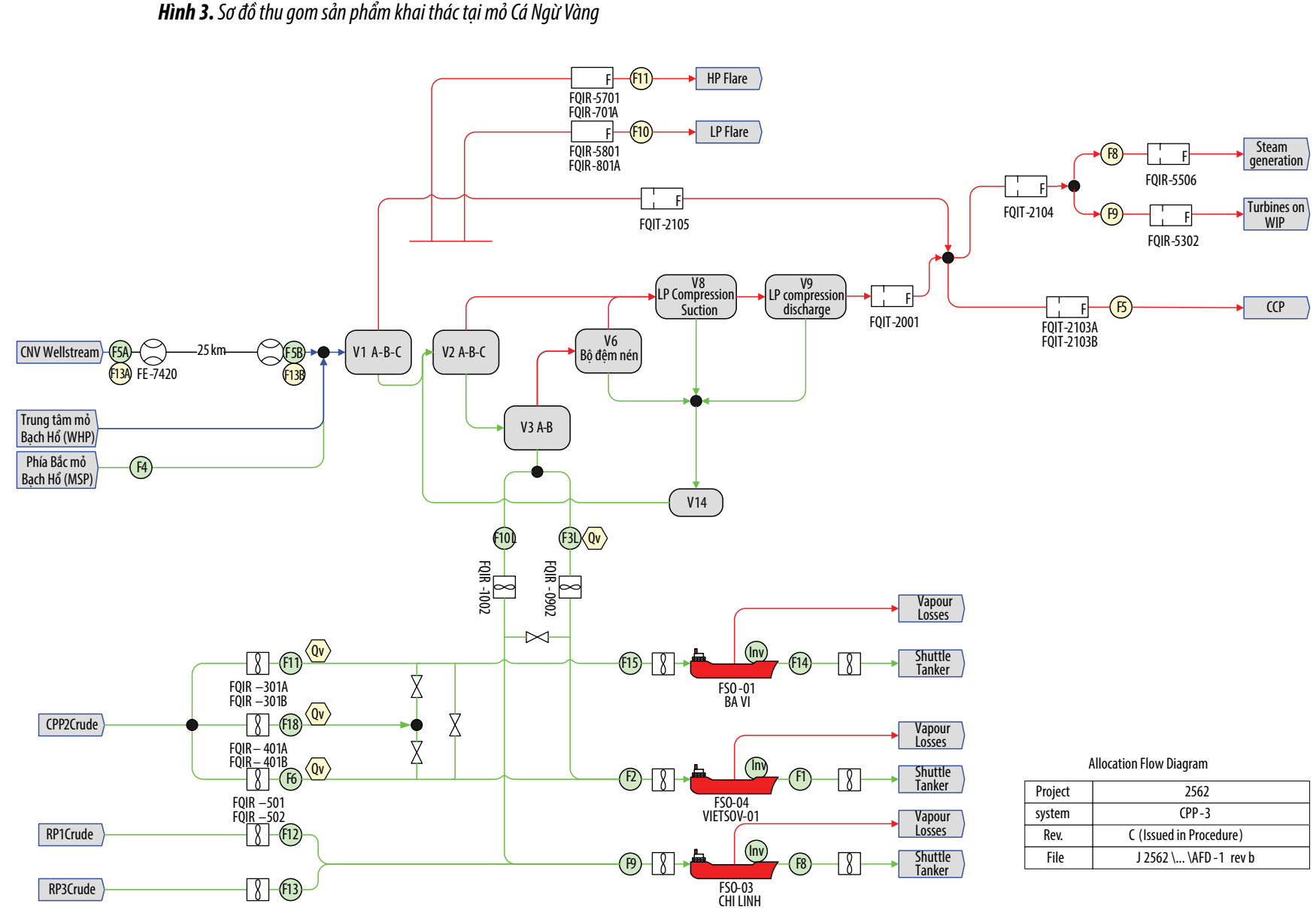

dầu Cá Ngừ Vàng được quy về điều kiện chuẩn thông qua hệ số co ngót $\mathrm{S}$ từ lượng dầu $\mathrm{V}\left(\mathrm{m}^{3}\right)$ đo được ở điều kiện vận hành:

$$
\begin{aligned}
Q_{\text {SCO/CTP___FSO }} & =V_{\text {oil/CTP2 }} \times S_{\text {oil/CTP2 }} \\
Q_{\text {SCO/CTP3_CNVFSO }} & =V_{\text {oil/RP3 }} \times S_{\text {oil/CTP3_CNV }}
\end{aligned}
$$

$\mathrm{S}_{\text {oil/CTP3_cnV }}$ được xác định theo công thức thực nghiệm trên cơ sở kết quả đo hệ số co ngót của hỗn hợp dầu Bạch Hổ và Cá Ngừ Vàng theo các tỷ lệ khác nhau, ví dụ:

$$
\begin{aligned}
& S\left(P_{\text {Pump }^{\prime}} T_{\text {Pump }} \text { Mixratio }\right)=a \times P_{\text {Pump }}+b \times T_{\text {Pump }}+ \\
& c \times \text { Mixratio }+d \\
& b=-8,9 e-04 ; \\
& c=-4,06 e-03 ; \\
& d=9,98 e-01 ;
\end{aligned}
$$

Mixratio = Tỷ lệ dầu Cá Ngừ Vàng so với dầu Bạch Hổ theo khối lượng;

$\mathrm{P}_{\text {Pump' }} \mathrm{T}_{\mathrm{Pump}}$ : Áp suất và nhiệt độ bơm dầu. 
Hỗn hợp dầu khí mỏ Cá Ngừ Vàng được vận chuyển về bình tách CNV separator, tách khí và đo lượng lỏng trước khi trộn với dầu mỏ Bạch Hổ.

Hệ số bất cân bằng:

$$
K_{\text {imb }}=\frac{Q_{\text {SCO/FSO }}}{Q_{\text {SCO/CTP_2_FSO }}+Q_{\text {SCO/CTP3_CNVFSO }}}
$$

Lượng dầu $\mathrm{Q}_{\mathrm{SCO} / \mathrm{CN} \mathrm{F}_{\mathrm{FsO}}}$ được xác định dựa trên tổ hợp số liệu thể hiện sự khác biệt giữa lượng dầu đo được tại bình tách CNV separator và lượng dầu Cá Ngừ Vàng đo khi bơm đi tàu trong cùng một điều kiện, qua hệ số $\mathrm{K}_{\mathrm{adj}}$.

$$
K_{\text {adj }}=\frac{Q_{\text {SCO/CNV_FSO }}}{Q_{\text {SCO/CNV_Separator }}}
$$

Trong đó:

$\mathrm{Q}_{\mathrm{SCO} / \mathrm{CN} \text { _Separator }}$ lượng dầu Cá Ngừ Vàng đo được tại CNV separator.

Lượng dầu chia cho mỏ Cá Ngừ Vàng được xác định như sau:

$$
Q_{\text {Allocated_SCO/CNV_FSO }}=Q_{\text {SCO/CNV_Separator }} K_{\text {adj }} \times K_{\text {imb }}
$$

\subsection{Phân chia sản phẩm mỏ Thiên Úng}

Sản phẩm khai thác từ mỏ Thiên Ưng được vận chuyển về $B K-4 A$ mỏ Bạch Hổ dưới dạng hỗn hợp lỏng - khí. Từ BK$4 \mathrm{~A}$, khí và condensate được đưa qua BK-4 sau đó theo 2 đường ống đường kính 12 inch về $B K-2$, tiếp sau đó sang C1-5 trên CPP-2 để tách khí, khí tách ra với áp suất khoảng 10 barg được đưa sang giàn nén trung tâm CCP của mỏ Bạch Hổ. Condensate sau C1-5 được chia làm 2 phần: (i) được bơm vào đường ống khí hiện hữu Bạch Hổ - Dinh Cố để đi vào bờ với công suất bơm lớn nhất là 56 m²/giờ
(2 máy bơm công suất mỗi bơm là 28 m³/giờ), khối lượng condensate bơm vào bờ được xác định bởi bộ đo Coriolis FT-1514A; (ii) condensate C1-5 sau khi đi qua bộ đo FT1514B được hòa trộn với dầu Bạch Hổ sau bình tách sử dụng điện trường cao $(\mathrm{EG})$ sau đó hỗn hợp được đưa về bình buffer C2-3 để tách khí. Hỗn hợp dầu và condensate sau khi tách khí được bơm sang FSO VSP-01 để tàng chứa và xuất bán.

Sơ đồ thu gom vận chuyển và phân chia dòng dầu được thể hiện tại Hình 5.

Do lượng condensate từ Thiên Ưng về CPP-2 chỉ xuất hiện khi phóng thoi đẩy lỏng đường ống Nam Côn Sơn 2 với tần suất dự kiến khoảng 1 lần/tháng và mỗi lần phóng thoi lượng condensate chưa ổn định được đưa sang FSO cũng chỉ dao động trong khoảng 1.500 - 1.800 tấn, nên mô hình phân chia dựa trên nguyên lý khấu trừ (by difference) đã được chấp thuận áp dụng, điều đó có nghĩa là kiểm soát sự thay đổi của dòng condensate C1-5 sau khi đi qua bộ đo Coriolis FT-1514B dưới dạng khối lượng (mass).

Do condensate tách ra trong $\mathrm{C} 1-5$ và được xác định bởi bộ đo FT-1514B là dòng chất lưu ở điều kiện áp suất cao 10 - 11 barg và nhiệt độ thấp khoảng $24-28^{\circ} \mathrm{C}$ khi đi qua các quá trình công nghệ trên CPP-2 và FSO một lượng khí sẽ được tách ra, khối lượng ban đầu của condensate sẽ giảm. Như vậy, lượng hao hụt condensate sẽ là một hàm phụ thuộc vào thành phần cấu tử của condensate Thiên Ung, điều kiện tách khí trong bình tách C1-5, C2-3, điều kiện tách khí trên FSO trong tank công nghệ và tank chứa và quá trình công nghệ này có thể được mô phỏng bằng phần mềm HYSYS (process modelling) hoặc bằng thực nghiệm.

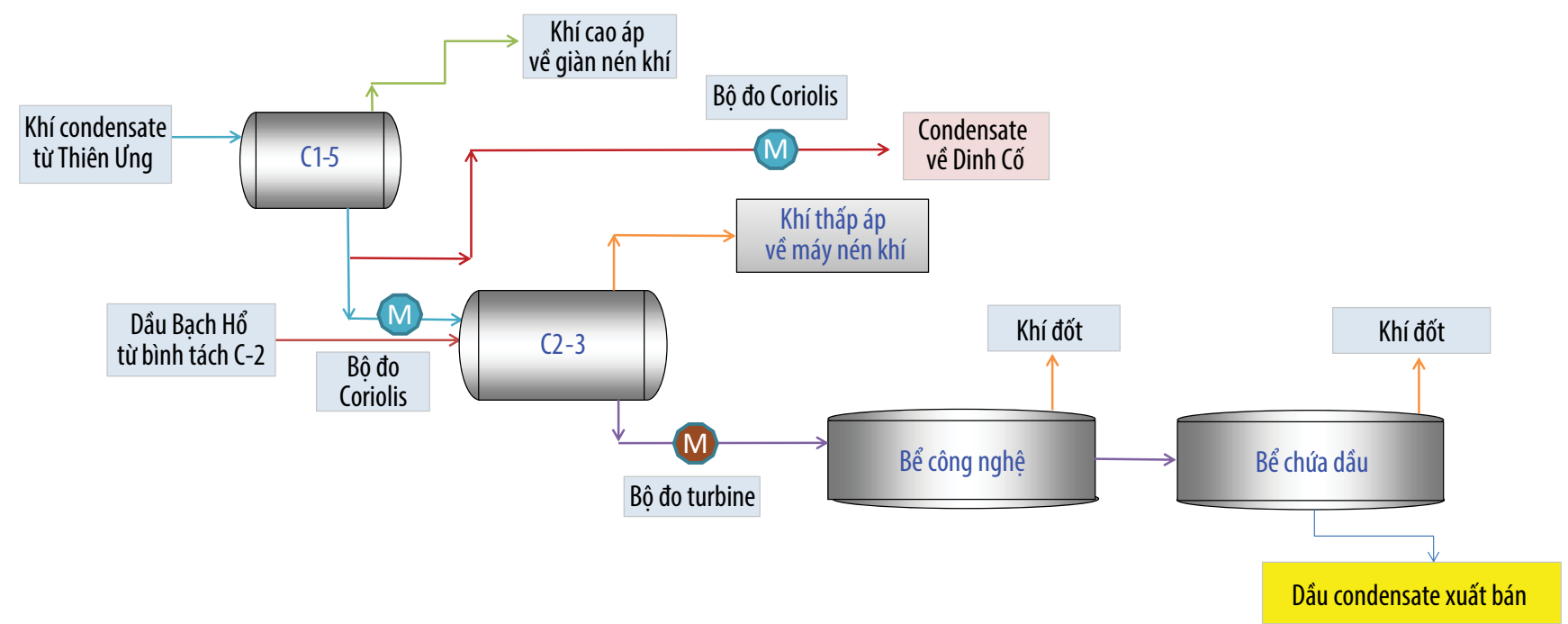

Hinh 5. Sơ đồ thu gom condensate Thiên Ung 
Sau mỗi lần phóng thoi đẩy sản phẩm lỏng ra khỏi đường ống Nam Côn Sơn 2 thì thành phần, tính chất và khối lượng của condensate đến C1-5 đều có sự biến đổi. Nguyên nhân là do có một số tác nhân thay đổi như sau:

- Tỷ lệ khai thác của các giếng trên BK-TNG;

- Tỷ lệ khí của mỏ ĐH trong thành phần chung;

- Tổng lưu lượng khí và condensate vận chuyển qua đường ống Nam Côn Sơn 2 thay đổi;

- Thời gian giữa các lần phóng thoi, hay thời gian lưu của condensate trong đường ống càng lâu thì thành phần của condensate càng nặng lên;

- Nhiệt độ nước biển bao bọc xung quanh đường ống thay đổi theo mùa.

Kết quả của quá trình tính toán tổn hao condensate C1-5 được lấy theo mô hình HYSYS, dựa trên cân bằng pha của các cấu tử trong pha khí và pha lỏng. Trong thực tế thì quá trình tách khí trong tank công nghệ và tank hàng trên FSO sẽ kéo dài nhiều ngày (điều này đã được kiểm chứng bằng mô hình HYSYS khi không có condensate Thiên Ưng, kết quả mô hình HYSYS tương đương với các phương pháp khác).

Kết quả của quá trình phân chia theo nguyên lý khấu trừ là khối lượng (mass).

Nhiệt độ và áp suất làm việc trung bình của bình tách C1-5 được tính trên cơ sở trung bình trọng số theo công thức:

$$
\begin{aligned}
T_{C 1-5} & =\frac{\sum_{1}^{N} T T 1514 B_{i} \times\left(F T 1514 A_{i}+F T 1514 B_{i}\right)}{\sum_{1}^{N}\left(F T 1514 A_{i}+F T 1514 B_{i}\right)} \\
P_{C 1-5} & =\frac{\sum_{1}^{N} P T 1513_{i} \times\left(F T 1514 A_{i}+F T 1514 B_{i}\right)}{\sum_{1}^{N}\left(F T 1514 A_{i}+F T 1514 B_{i}\right)}
\end{aligned}
$$

Trong đó các dữ liệu được lấy từ file excel trích xuất từ Flow Computer như sau:

TT1514B: Tín hiệu tại thời điểm i về nhiệt độ bình tách C1-5 $\left({ }^{\circ} \mathrm{C}\right)$;

PT1513: Tín hiệu tại thời điểm i về áp suất bình tách C1-5 (barg);

FT1514A: Tín hiệu tại thời điểm i về lưu lượng condensate bơm về bờ (tấn/giờ);

FT1514B: : Tín hiệu tại thời điểm i về lưu lượng condensate đưa sang C2-3 (tấn/giờ);

$\mathrm{N}$ : Tổng số dòng dữ liệu trong trong file excel đại diện cho đợt phóng thoi.
Nhiệt độ và áp suất làm việc trung bình của bình tách C2-3 trên CPP-2 được tính trên cơ sở trung bình trọng số theo công thức:

$$
\begin{aligned}
T_{C 2-3} & =\frac{\sum_{1}^{N} T T 513_{i} \times F T 1514 B_{i}}{\sum_{1}^{N} F T 1514 B_{i}} \\
P_{C 2-3} & =\frac{\sum_{1}^{N} P T 513_{i} \times F T 1514 B_{i}}{\sum_{1}^{N} F T 1514 B_{i}}
\end{aligned}
$$

Trong đó, các dữ liệu được lấy từ file excel trích xuất từ Flow Computer như sau:

TT513: Tín hiệu tại thời điểm i về nhiệt độ bình tách $\mathrm{C} 2-3\left({ }^{\circ} \mathrm{C}\right)$;

PT513: Tín hiệu tại thời điểm i về áp suất bình tách C2-3 (barg);

FT1514B: Tín hiệu tại thời điểm i về lưu lượng condensate đưa sang C2-3 (tấn/giờ);

$\mathrm{N}$ : Tổng số dòng dữ liệu trong trong file excel đại diện cho đợt phóng thoi.

Tính toán thành phần khối lượng cấu tử mẫu condensate:

$$
x_{i R}=\frac{x_{i} \times \rho_{o i l}+G O R \times y_{i} \times \rho_{g}}{\rho_{o i l}+G O R \times \rho_{g}}
$$

$\mathrm{x}_{\mathrm{iR}}$ :Thành phần khối lượng cấu tử i trong mẫu condensate C1-5 được tái tạo;

$\mathrm{x}_{\mathrm{i}}$ : Thành phần khối lượng cấu tử i trong mẫu condensate ổn định;

$\mathrm{y}_{\mathrm{i}}$ :Thành phần khối lượng cấu tử i trong mẫu khí được tách ra;

GOR: Tỷ số khí dầu $\left(\mathrm{sm}^{3} / \mathrm{sm}^{3}\right)$;

$\rho_{\text {oil }}$ : Mật độ của condensate ổn định được quy về điều kiện chuẩn $15^{\circ} \mathrm{C}$;

$\rho_{\mathrm{g}}$ : Mật độ của khí tách ra được quy về điều kiện chuẩn $15^{\circ} \mathrm{C}$.

Tính toán MW của condensate C1-5 trên cơ sở tính toán tái tạo từ $\mathrm{MW}$ của condensate ổn định và $\mathrm{MW}$ khí tách:

$$
M W_{C 1-5}=\frac{\rho_{\text {oil }}+G O R \times \rho_{g}}{\frac{\rho_{\text {oil }}}{M W_{\text {oil }}}+\frac{G O R \times \rho_{g}}{M W_{g}}}
$$

$\rho_{\text {oil }}$ : Mật độ của condensate ổn định được quy về điều kiện chuẩn $15^{\circ} \mathrm{C}$;

$\rho_{g}$ : Mật độ của khí tách ra được quy về điều kiện chuẩn $15^{\circ} \mathrm{C}$; 


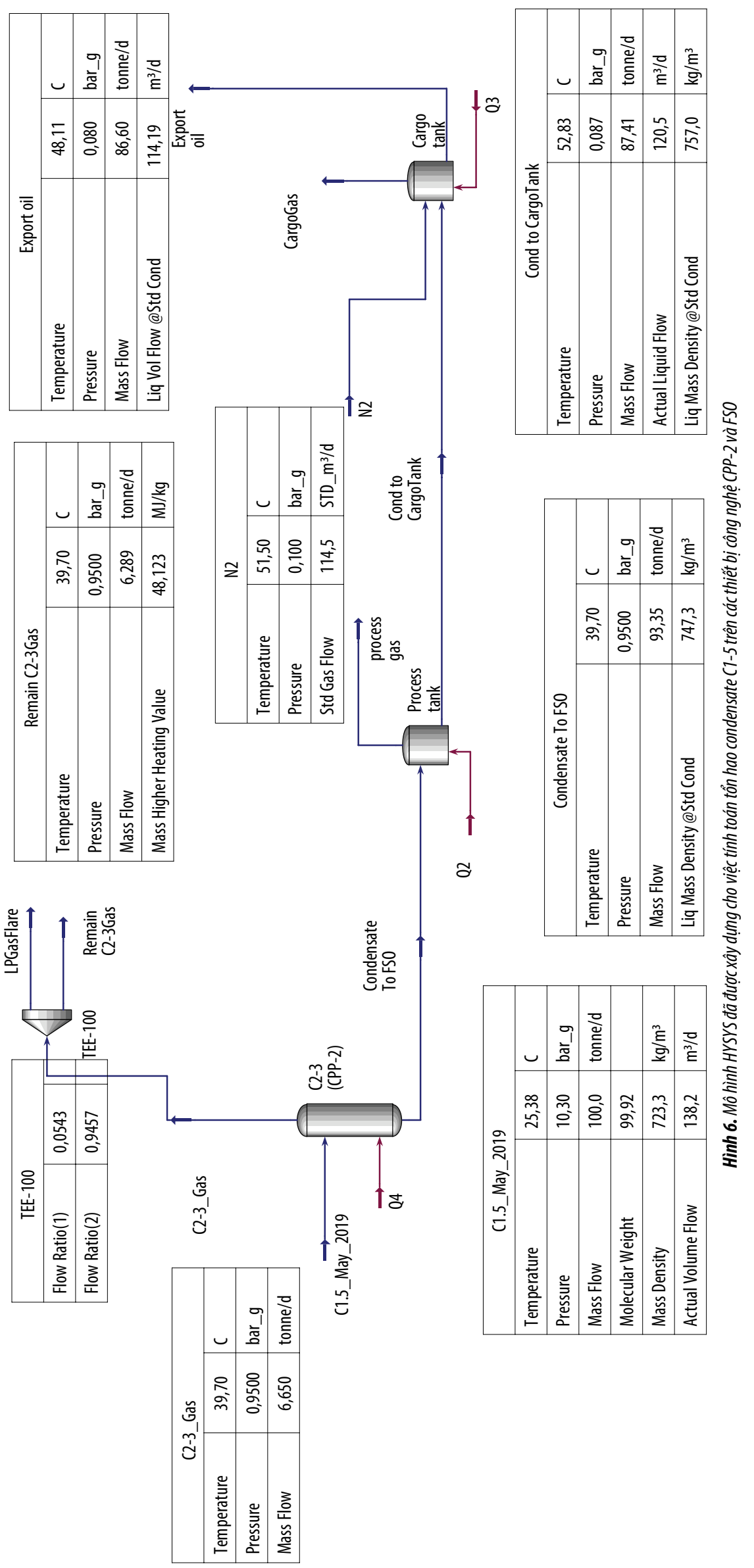

$\mathrm{MW}_{\text {oil }}$ : Trọng lượng phân tử của condensate ổn định được xác định trong phòng thí nghiệm bằng;

$\mathrm{MW}_{\mathrm{g}}$ : Trọng lượng phân tử của khí tách ra (Flashed gas) được xác định dựa trên thành phần khí.

Mô hình mô phỏng cho tính toán lượng condensate Thiên Ưng sau khi được nhập đầy đủ các thông số công nghệ và thành phần tính chất của các cấu tử và phân đoạn (Hình 6).

Kết quả tính toán từ mô hình mô phỏng cho phép xác định lượng condensate Thiên Úng còn lại tàng trữ và xuất bán trên FSO.

Dựa trên các bộ số liệu từ mô hình mô phỏng cho phép chúng ta xây dựng công thức thực nghiệm áp dụng cho condensate Thiên Ưng đánh giá sự hao hụt trong quá trình công nghệ (Hình 7). Công thức thực nghiệm cho phép đánh giá nhanh mất mát condensate Thiên Ưng trong hệ thống thu gom xử lý tàng trữ theo mối quan hệ phụ thuộc của các thông số hệ thống công nghệ và tính chất chất lưu của condensate Thiên Ưng.

$$
\begin{gathered}
Y=a \times X_{1}+b \times X_{2}+c \times X_{3}+d \times X_{4}+ \\
e \times X_{5}+f \times X_{6}+g \times X_{7}+h \times X_{8}+i \times \\
X_{9}+k
\end{gathered}
$$

Trong đó:

$$
\begin{aligned}
& a=73,77896904 \\
& b=-0,892855713 \\
& c=6,208990561 \\
& d=0,581383216 \\
& e=0,709107773 \\
& f=-0,30933858 \\
& g=-90,30695494 \\
& h=0,874029514 \\
& i=81,81200351 \\
& j=-0,204966919 \\
& k=-0,892855713
\end{aligned}
$$




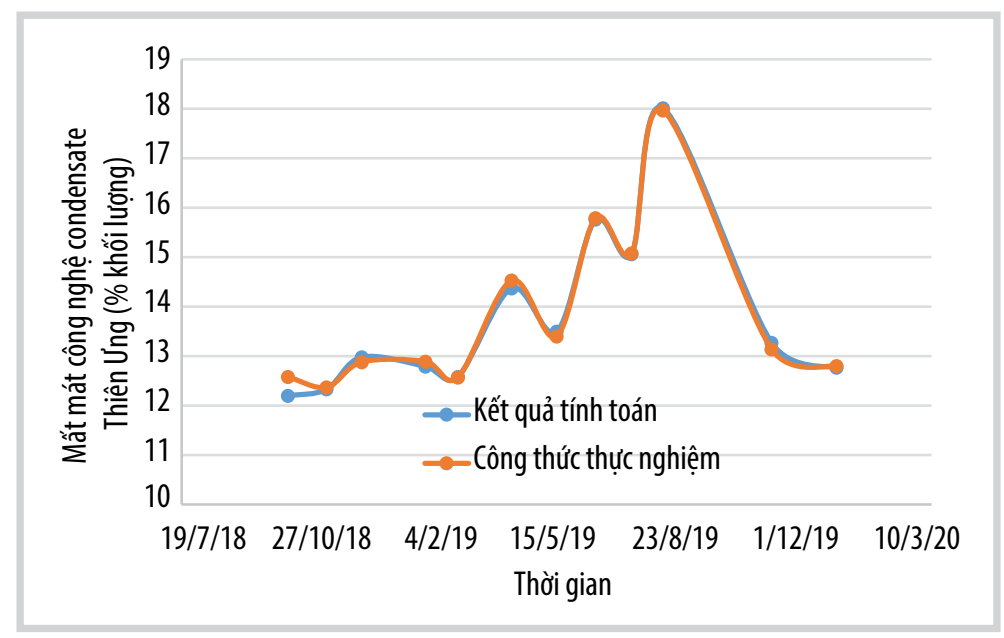

Hinh 7. So sánh kết quả tính toán và công thức thực nghiệm

Y: Lượng mất mát công nghệ của condensate Thiên Ưng (\% khối lượng);

\footnotetext{
$\mathrm{X}_{1}$ : Nhiệt độ C-1-5 $\left({ }^{\circ} \mathrm{C}\right)$;

$\mathrm{X}_{2}$ : Áp suất C-1-5 (bar);

$X_{3}$ : Nhiệt độ C-2-3 $\left(^{\circ} \mathrm{C}\right)$;

$\mathrm{X}_{4}$ : Áp suất C-2-3 (bar);

$X_{5}$ : Nhiệt độ tank công nghệ của FSO $\left({ }^{\circ} \mathrm{C}\right)$;

$\mathrm{X}_{6}$ : Áp suất tank công nghệ của FSO (bar);
}

$\mathrm{X}_{7}$ : Nhiệt độ tank tàng trữ của $\mathrm{FSO}\left({ }^{\circ} \mathrm{C}\right)$;

$\mathrm{X}_{8}$ : Áp suất tank tàng trữ (bar);

$\mathrm{X}_{9}$ : Mật độ condensate Thiên Úng tại điều kiện C-1-5 $\left(\mathrm{kg} / \mathrm{m}^{3}\right)$.

\section{Kết luận}

Vietsovpetro đã nghiên cứu, áp dụng và phát triển các mô hình phân chia dầu khí khác nhau đáp ứng các đặc thù của mỗi trường hợp kết nối. Mô hình kết nối theo quy trình phân chia ngược cho phép xác định lượng dầu phân chia cho các nguồn dầu với kết quả được nhiều bên chấp nhận. Sử dụng các công cụ mô phỏng tính toán cũng là phương thức xác định phân chia dầu khí có độ tin cậy cao. Việc áp dụng các công thức thực nghiệm cho phép đánh giá nhanh về kỹ thuật sự thay đổi của lưu lượng chất lưu trong hệ thống khi đi qua các quá trình xử lý công nghệ khác nhau.

\section{Tài liệu tham khảo}

[1] American Petroleum Institute, "Manual of petroleum measurement standards chapter 20.3 Measurement of multiphase flow", 2013.

\title{
RESEARCH AND DEVELOPMENT OF PRODUCT DISTRIBUTION MODELS FOR VIETSOVPETRO'S TIE-IN FIELDS
}

\author{
Tran Le Phuong', Le Dang Tam ', Chu Van Luong', Pham Thanh Vinh', Nguyen Vi Hung', Tong Canh Son' \\ Nguyen Viet Van'2, Do Duong Phuong Thao', A.G. Axmadev', Chau Nhat Bang', Nguyen Huu Nhan', Doan Tien Lu' \\ Tran Thi Thanh Huyen', Le Thi Doan Trang', Bui Mai Thanh Tu' \\ 'Vietsovpetro \\ ${ }^{2}$ Hoang Long - Hoan Vu JOC \\ Email:vinhpt.rd@vietsov.com.vn
}

\section{Summary}

Oil and gas field tie-in is a solution to take advantage of the existing infrastructure of major oil and gas fields to connect with and develop the marginal fields. This approach allows to increase the economic efficiency of small and medium reserves, open prospects for developing and bringing small and marginal fields into early production.

The field tie-in process faces different technical and economic challenges, including connecting and gathering capability, and levels of technological modification for receiving and distributing products. In the case of fields connected to the technological system of other owners, product distribution has important implications relating to the direct interests of the investors.

The article analyses the product distribution models which Vietsovpetro is applying to the tie-in fields, evaluating the possibility of updating/upgrading simulation softwares with high reliability, allowing rapid technical assessment of the changes in the flow of fluid in the system through technological treatment processes.

Key words: 0il and gas field tie-in, oil and gas transportation, product distribution. 